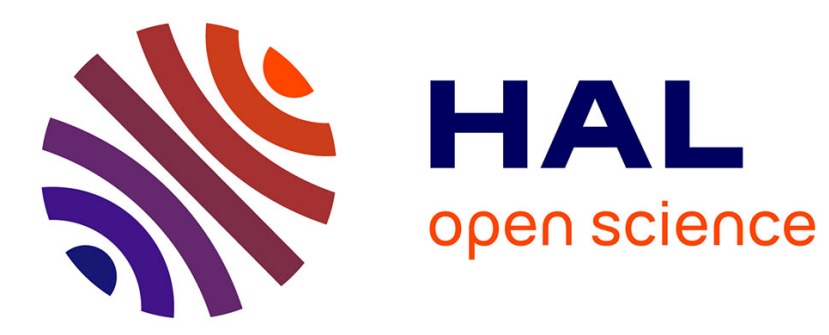

\title{
Oxidation assisted fatigue crack growth under complex non-isothermal loading conditions in a nickel base superalloy.
}

\author{
Juan Antonio Ruiz-Sabariego, Sylvie Pommier
}

\section{- To cite this version:}

Juan Antonio Ruiz-Sabariego, Sylvie Pommier. Oxidation assisted fatigue crack growth under complex non-isothermal loading conditions in a nickel base superalloy.. International Journal of Fatigue, 2009, 31 (11-12), pp.1724-1732. 10.1016/j.ijfatigue.2009.03.009 . hal-00417877

\section{HAL Id: hal-00417877 \\ https://hal.science/hal-00417877}

Submitted on 17 Sep 2009

HAL is a multi-disciplinary open access archive for the deposit and dissemination of scientific research documents, whether they are published or not. The documents may come from teaching and research institutions in France or abroad, or from public or private research centers.
L'archive ouverte pluridisciplinaire HAL, est destinée au dépôt et à la diffusion de documents scientifiques de niveau recherche, publiés ou non, émanant des établissements d'enseignement et de recherche français ou étrangers, des laboratoires publics ou privés. 


\title{
OXIDATION ASSISTED FATIGUE CRACK GROWTH UNDER COMPLEX NON-
}

\section{ISOTHERMAL LOADING CONDITIONS IN A NICKEL BASE SUPERALLOY.}

\author{
Juan Antonio Ruiz-Sabariego ${ }^{1}$, Sylvie Pommier ${ }^{1}$ \\ ${ }^{1}$ LMT-Cachan, (ENS Cachan/CNRS/UPMC/UniverSud Paris), 61, avenue du Président Wilson, \\ 94235 Cachan, France
}

\begin{abstract}
This paper deals with the prediction of fatigue crack growth at high temperatures in the N18 nickel base superalloy, which is employed by Snecma for turbine disc applications. This material and other nickel base superalloys were widely studied in the past under isothermal conditions and constant amplitude fatigue. Dwell time effects are observed which are attributed, in this material, to grain boundary oxidation. The main objective of this research is to use this knowledge to model the fatigue crack growth rate in the N18 nickel base superalloy when complex “missions” are encountered. This implies variable amplitude and non-isothermal loading conditions $\left(450^{\circ} \mathrm{C}-650^{\circ} \mathrm{C}\right)$. For this purpose, an incremental fatigue crack growth model which was originally developed for isothermal variable amplitude loading conditions was extended so as to be applicable to non-isothermal loading conditions. In addition, the incremental form of the fatigue crack growth law in this model is very useful to account for the coupling effect between fatigue and timedependent phenomena such as creep or oxidation. In the present case, the effect of the environment was modelled as a competition between two phenomena: a detrimental effect of grain boundary oxidation ahead of the crack tip and a beneficial effect of the growth of a passivation layer of oxides on the freshly created crack surfaces. The model was used to simulate fatigue crack growth under complex cycles at high temperature and the comparisons with experimental results are satisfactory.
\end{abstract}

Keywords: fatigue crack growth, nickel base superalloy, oxidation, environment, high temperature.

\section{Nomenclature}

- CTG

- $d a / d t$

- $K_{I}^{\infty}$.

- $v(x, t)$

- $\underline{u}_{I}^{e}(\underline{x}), \underline{u}_{I}^{c}(\underline{x})$

$-d K_{I}^{*} / d t, d \rho_{I} / d t$

$-b_{c}, a_{c}$ crack tip region

rate of production of cracked area per unit length of the crack front. nominal applied stress intensity factor velocity of the point $\underline{x}$ in the CTG elastic and plastic reference spatial fields intensity factor rates of $\underline{u}_{I}^{e}(\underline{x})$ and $\underline{u}_{I}^{c}(\underline{x})$ size and displacement rate of the elastic domain of the CTG 
- $a_{x m}$

- $\alpha$ and per unit of $\rho_{I}$ at fixed time.

$-\beta$ absence of a passivation layer of oxides.

- $m$

\section{Introduction}

The aircraft industry faces the problem of predicting fatigue fracture of their aircraft engines parts under variable loads, variable thermal conditions and detrimental environmental conditions. An accurate prediction of the fatigue crack growth rate under complex loading conditions is useful to improve the inspection intervals of industrial components. However, predicting fatigue crack growth in metals under realistic loading schemes remains difficult because the fatigue crack growth rate is very sensitive to load history. As a matter of fact, constrained plasticity at crack tip has been known for decades to induce history effects in fatigue crack growth [1-7] and these effects are closely related to the cyclic elastic-plastic behaviour of the material [8,9]. Therefore, a strategy was proposed to identify a global history-dependent fatigue crack growth model, using finite element computations that include a cyclic elastic-plastic constitutive model identified for each material studied [10-12]. Once identified, this model consists finally of a set of about ten scalar derivative equations, which therefore allows the computation of typically a million variable amplitude fatigue cycles within a minute. In this model, the crack growth rate is a time derivative equation da/dt. This formulation explicitly avoids the need of a cycle counting method [10-11]. In addition, it facilitates the writing of coupled multi-physic problems, such as oxidation assisted fatigue crack growth and non-isothermal fatigue. This model was identified and validated at room temperature for a low carbon steel using constant and variable amplitude loading fatigue crack growth experiments [12].

The aim of the present research is to examine how that method can be extended to consider oxidation assisted fatigue crack growth in a nickel base superalloy when variable amplitude and non-isothermal loading conditions are encountered. In the following, the method employed to build the model is briefly recalled and then the application to fatigue crack growth under variable amplitude loading and non-isothermal conditions in the N18 nickel base superalloy is discussed.

\section{Multiscale strategy}

Let us briefly summarize what has already been done for mode I fatigue crack growth under variable amplitude loading conditions. The fatigue crack growth model is based on the assumption that the fatigue crack growth rate is a function of crack tip plasticity. First of all, a global measure 
$d \rho_{I} / d t$ of the rate of crack tip plasticity is introduced. Then the model is divided into two parts. The first part provides the fatigue crack growth rate $d a / d t$ as a function of $d \rho_{I} / d t$ and is established using the results of fatigue crack growth experiments. The second part allows predicting $d \rho_{I} / d t$ according to the loading conditions and the values of a set of internal variables introduced to account for history effects. This second part is established using elastic-plastic finite element computations. Details about this model can be found in previous publications [10-12].

The second part of the model can be considered as a global cyclic elastic-plastic constitutive model for the crack tip region. A multiscale strategy was proposed in order to benefit on the one hand from the ability of the local FE model to account for detailed and complex material behaviours and on the other hand from the computational efficiency of global crack growth criteria. It assumes that the velocity field in the crack tip region is partitioned into elastic and plastic parts which are also assumed to be the product of an intensity factor and of a reference spatial field (Eq. 1).

$$
\underline{v}(\underline{x}, t) \approx \frac{d K_{I}^{*}(t)}{d t} \underline{u}_{I}^{e}(\underline{x})+\frac{d \rho_{I}(t)}{d t} \underline{u}_{I}^{c}(\underline{x})
$$

When the material behaviour is elastic, the intensity factor rate $d K_{I}^{*} / d t$ of the elastic field $\underline{u}_{I}^{e}(\underline{x})$ is equal to the nominal applied stress intensity factor rate $d K_{I}^{\infty} / d t$. When crack tip plasticity occurs, $d K_{I}^{*} / d t$ diverges slightly from $d K_{I}^{\infty} / d t$. Furthermore, the intensity factor rate of the plastic field $\underline{u}_{I}^{c}(\underline{x})$, denoted by $d \rho_{I} / d t$ becomes non negligible and is used as a global measure of plastic deformation within the crack tip region. Numerically, it is always possible to approximate a velocity field as it is done in Eq. 1, using a proper orthogonal decomposition such as the KarhunenLoeve transform. In practice, $\underline{u}_{I}^{e}(\underline{x})$ is defined as the finite element solution of a $2 \mathrm{D}$ plane strain elastic problem with boundary conditions such that $K_{I}^{\infty}=1 M P a \sqrt{m}$. Then a 2D plane strain elasticplastic finite element computation is performed, with $K_{I}^{\infty}$ increasing from zero to a maximum value chosen to be consistent with a fatigue application (i.e. a loading ramp from $K_{I}^{\infty}=0$ up to $K_{I}^{\infty}=40 \mathrm{MPa} \sqrt{m}$, for instance). At the end of the computation, $d K_{I}^{*} / d t$ is obtained by projecting the elastic-plastic numerical solution onto the reference elastic field $\underline{u}_{I}^{e}(\underline{x})$. The rest is partitioned into an intensity factor and a reference field using the Karhunen-Loeve transform. This allows the building of a numerical reference solution for $\underline{u}_{I}^{c}(\underline{x})$, which is non-dimensioned so that $d \rho_{I} / d t$ could also be read as the mean rate of the plastic part of the displacement between the crack faces in 
micrometers. Alternatively, an analytical expression for $\underline{\underline{u}}_{I}^{c}(\underline{x})$ can also be used which is based on the theory of distributed dislocations [13]. In such a case, $\underline{u}_{I}^{c}(\underline{x})$ can be defined as the displacement field around an edge dislocation aligned with the crack plane and with a Bürgers vector equal to 1 . In both cases, once the reference fields $\underline{u}_{I}^{e}(\underline{x})$ and $\underline{u}_{I}^{c}(\underline{x})$ are known for a material, they can be used to extract $d \rho_{I} / d t$ as a function of $d K_{I}^{\infty} / d t$ from any complex elastic-plastic FE computation of a cracked body.

Once the reference fields $\underline{u}_{I}^{e}(\underline{x})$ and $\underline{u}_{I}^{c}(\underline{x})$ are defined, the approximation in Eq. 1 is performed at each step of a FE computation using an automated post-processing routine based on the least square method. The mean square error between the computed velocity field during the step $\underline{v}(\underline{x}, t)$ and the approximated one $\left(d K_{I}^{*} / d t\right) \underline{u}_{I}^{e}(\underline{x})+\left(d \rho_{I} / d t\right) \underline{u}_{I}^{c}(\underline{x})$ is also computed at each step of the FE computation. This error is always found to remain well below $10 \%$.

The finite element method and the post-treatment routine are then employed to generate evolutions of $d \rho_{I} / d t$ under various loading cases, including cyclic loadings with either a stationary crack (Fig. 1) or a growing crack.

Then, a global empirical model, developed within the framework of dissipative processes, is associated to these evolutions and allows predicting $d \rho_{I} / d t$ as a function of $d K_{I}^{\infty} / d t$ and of a set of internal variables.

For instance, at each load's reversal (Fig. 1), it is observed that there is a domain within which no variation of $\rho_{I}$ is observed. Since $\rho_{I}$ is a measure of crack tip plasticity, this domain (E in Fig. 1) can be considered as an elastic domain for the crack tip region. If the material does not display any isotropic hardening, it was shown, using FE computations, that the size of the elastic domain (E) is constant in a $\left(\rho_{I}, K_{I}^{\infty}\right)$ diagram (Fig. 1). That size, $b_{c}$, can be identified for a given material behaviour using an automated post-treatment routine on the curves generated using FE computations (Fig. 1). If the stress intensity factor range remains below $b_{c}$, then $d \rho_{I} / d t$ remains negligible.

If the stress intensity factor range exceeds $b_{c}$, the elastic domain (E in Fig. 1) moves. An internal variable $\left(\phi_{x c}=K_{I x c}^{2}\left(1-v^{2}\right) / E\right)$ is therefore introduced to define the position of the centre of the global elastic domain of the crack tip region. Since the size of the elastic domain is constant, the 
relation between $\Delta K_{I}^{\infty}$ and $\Delta \rho_{I}$ allows the characterization of the displacement of the centre of the elastic domain. This relation was determined using FE computations and a very simple equation can be used to represent the numerical results: $\Delta \rho_{I} \approx\left\langle\Delta K_{I}^{\infty}-b_{c}\right\rangle^{2} / a_{c}$. This result was used to propose an evolution law $\left(\partial \phi_{x c} / \partial \rho\right)$ for the centre of the elastic domain with respect to a plastic deformation including the two parameters $b_{c}$ and $a_{c}$ that are determined for a given material using FE computations.

The same approach is also employed to determine the evolution equation of the centre of the elastic domain when crack extension occurs $\left(\partial \phi_{x c} / \partial a\right)$, the evolution equation of the closure point $\left(\phi_{x m}\right)$, either when plastic deformation occurs $\left(\partial \phi_{x m} / \partial \rho\right)$ or when crack growth occurs $\left(\partial \phi_{x m} / \partial a\right)$, etc...

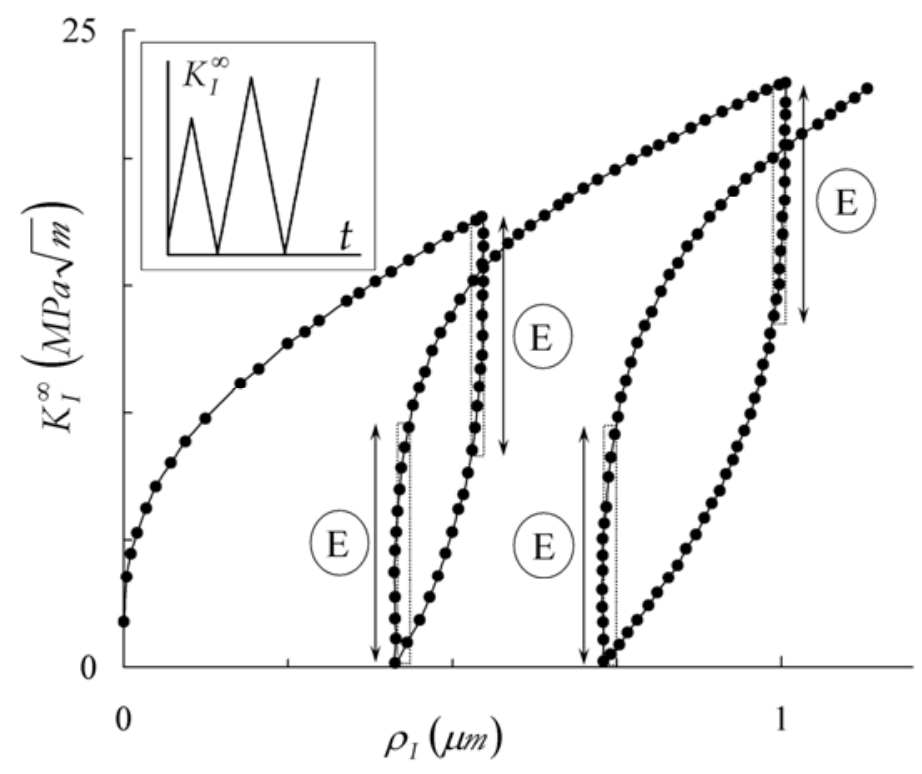

Figure 1. The nominal stress intensity factor $K_{I}^{\infty}$ is plotted against the plastic strain intensity factor $\rho_{I}$. Within the domain $(E)$, the variation of $\rho_{I}$. being negligible and the cracked structure is assumed to behave elastically.

Finally, the global cyclic elastic-plastic model for the crack tip region (Eq. 2) consists of about ten scalar partial derivative equations that allow computing $d \rho_{I} / d t$ as a function of the loading rate $d K_{I}^{\infty} / d t$ and of the state of the internal variables $V_{\text {int }}$ that were introduced to account for plasticity induced history effects. These equations can be found in previous publications $[11,12]$. 


$$
\frac{d \rho_{I}}{d t}=f\left(\frac{d K_{I}^{\infty}}{d t}, V_{\mathrm{int}}^{j}, P^{i}\right) \quad \text { and } \quad \frac{d V_{\mathrm{int}}^{j}}{d t}=f_{j}\left(\frac{d \rho_{I}}{d t}, \frac{d a}{d t}, P^{i}\right)
$$

The parameters $P^{i}$ in these equations are all determined, for a given material constitutive behaviour, using an automated post-treatment procedure of FE computations. Therefore, this part of the model requires only performing push-pull tests to identify the cyclic elastic-plastic behaviour of the material used in the FE computations. It is worth mentioning that the robustness of the model was checked carefully. More precisely, it is checked, for each material, that a linear variation of each parameter of the material cyclic elastic plastic constitutive law induces a linear variation of the parameters of the global cyclic elastic-plastic model for the crack tip region (Eq. 2) that are identified using the FE method.

Finally, a crack propagation law is also introduced which assumes that the crack growth rate is merely proportional to the plastic strain intensity factor rate. This equation derives directly from the well known $\triangle$ CTOD equation:

$$
\frac{d a}{d t}=\alpha\left|\frac{d \rho_{I}}{d t}\right|
$$

The coefficient $\alpha$ in Eq. 3 is adjusted using the results of one constant amplitude fatigue crack growth experiment $[11,12]$.

Gathering the global cyclic elastic-plastic constitutive model for the crack tip region, which predicts $d \rho_{I} / d t$ as a function of the loading conditions and of the loading history, and the crack propagation law, which predicts $d a / d t$ as a function of $d \rho_{I} / d t$, finally yields an incremental crack propagation model that accounts for plasticity induced history effects. This approach is operational for mode I fatigue crack growth, and, out of its numerical efficiency, it has the main advantage of avoiding cycle counting because of its incremental form. The model was identified for a low carbon steel by R. Hamam et al. [12] using push-pull tests and constant amplitude fatigue crack growth experiments at $\mathrm{R}=0$, and validated using fatigue crack growth experiments for stress ratios between $\mathrm{R}=-1$ and $\mathrm{R}=0.4$ and variable amplitude fatigue crack growth experiments.

\section{Non isothermal loading conditions}

Another advantage of an incremental formulation of the fatigue crack growth model is that its application to non-isothermal loading conditions is straightforward. As a matter of fact, the 
following procedure is currently applied for complex missions that include temperature variations. The rainflow counting method is used to extract cycles from the mechanical loading sequence. Then for each extracted cycle, a reference temperature is defined, and the fatigue crack growth rate is calculated for that temperature using the library of Paris laws for the studied material. Usually, to get conservative predictions, the reference temperature is the maximum temperature encountered during each cycle. However, this approach is overly-conservative if, for instance, the maximum of the temperature is reached when the stress reaches its minimum value. This problem vanishes if an incremental formulation $(d a / d t)$ is used rather than a cyclic formulation $(d a / d N)$.

For this purpose, the incremental fatigue crack growth model should be modified so as to account for temperature variations. First of all, the crack propagation law (Eq. 3) should be a function of the temperature. Secondly, the global cyclic elastic plastic model for the crack tip region (Eq. 2) should also be a function of the temperature, if the cyclic elastic-plastic behaviour of the material is function of the temperature.

\section{1 non-isothermal global cyclic elastic-plastic model for the crack tip region.}

First of all, the constitutive behaviour of the N18 nickel base superalloy was identified at $450^{\circ} \mathrm{C}$, $550^{\circ} \mathrm{C}, 600^{\circ} \mathrm{C}$ and $650^{\circ} \mathrm{C}$ using a database of experimental push-pull test results produced by Snecma and by other researchers [14,15].

This material is a powder metallurgy superalloy that was developed by Snecma for engine applications (turbine discs). Its chemical composition is given in Table 1. This material is particular due to its high $\gamma^{\prime}$ content (about 55\%). $\gamma^{\prime}$ precipitates are used to limit the mobility of dislocations at high temperature, which improves the creep resistance of the alloy. Such a $\gamma^{\prime}$ content is common in monocrystalline cast alloys (employed for blade applications) but very high for a polycrystalline forged material. Besides, the grains are equiaxed with a size around $15 \mu \mathrm{m}$. It displays high tensile and creep properties up to $700^{\circ} \mathrm{C}[16,17]$. As seen in Fig. 2, the evolutions of the cyclic elasticplastic behaviour of this material remain moderate between $450^{\circ} \mathrm{C}$ and $650^{\circ} \mathrm{C}$.

\begin{tabular}{|l|l|l|l|l|l|l|l|l|l|}
\hline $\mathbf{C}$ & $\mathbf{C o}$ & $\mathbf{N i}$ & $\mathbf{C r}$ & $\mathbf{M o}$ & $\mathbf{A l}$ & $\mathbf{T i}$ & $\mathbf{B}$ & $\mathbf{H f}$ & $\mathbf{Z r}$ \\
\hline 0.015 & 15.7 & base & 11.5 & 5.5 & 4.35 & 4.35 & 0.015 & 0.45 & 0.03 \\
\hline
\end{tabular}

Table 1 : Chemical composition of the N18 nickel base superalloy (weigth \%).

A Von Mises criterion and a two parameter Armstrong-Frederick non-linear kinematic hardening rule, standard in Abaqus, were employed to model the cyclic elastic-plastic behaviour of the 
material at $450^{\circ} \mathrm{C}, 550^{\circ} \mathrm{C}, 600^{\circ} \mathrm{C}$ and $650^{\circ} \mathrm{C}$ (Fig. 2) [18]. A very simple constitutive model was adopted to ensure the uniqueness of the set of material parameters identified for each temperature. This uniqueness is required because the parameters identified at these temperatures are interpolated to predict the cyclic elastic-plastic behaviour of the material at intermediate temperatures. The agreement between the experiments and the simulations is satisfactory but could be improved.
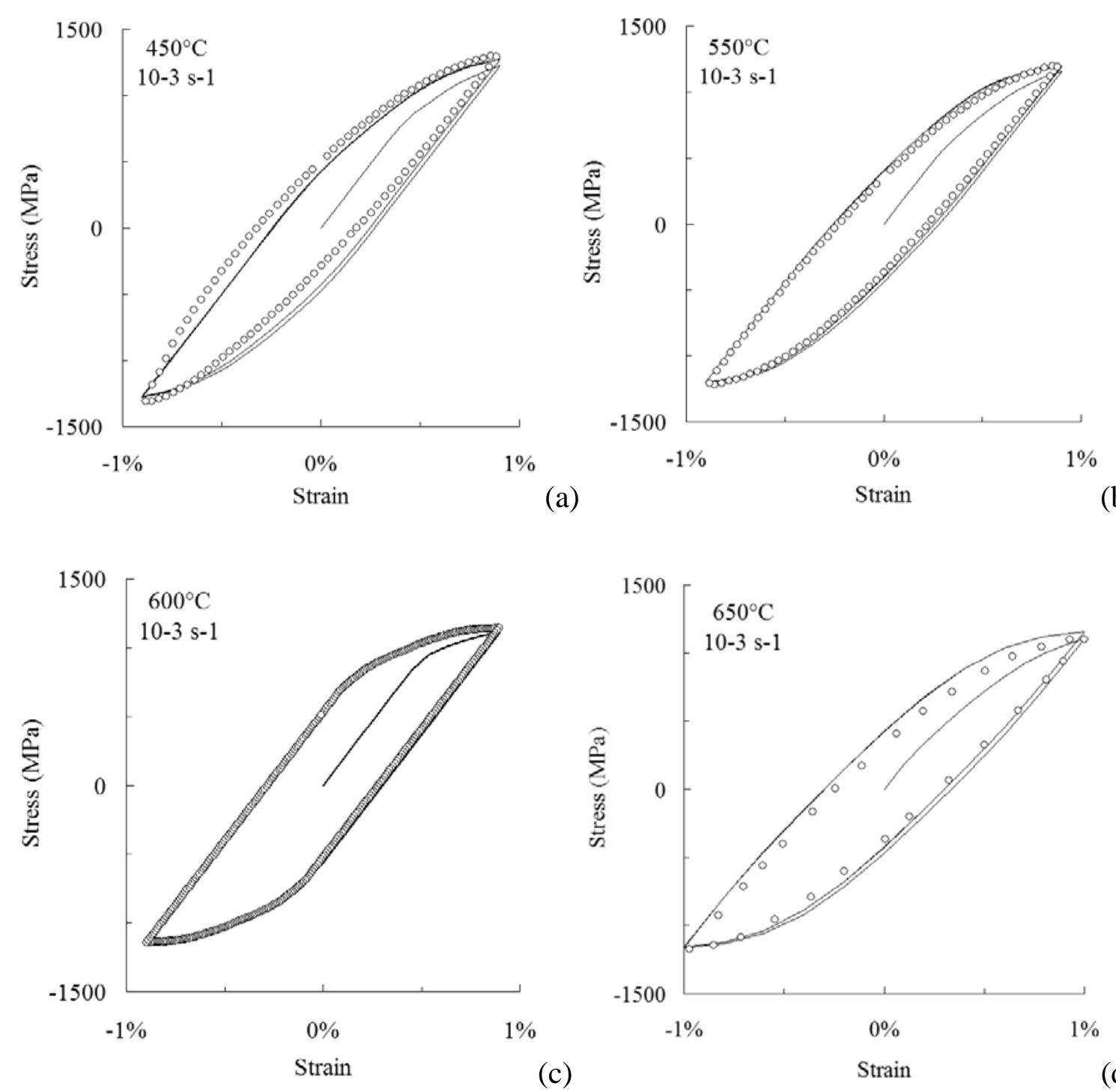

Figure 2. Comparison between experimental and simulated strain controlled push-pull tests on the $\mathrm{N} 18$ nickel base superalloy at (a) $450^{\circ} \mathrm{C}$, (b) $500^{\circ} \mathrm{C}$, (c) $600^{\circ} \mathrm{C}$ and (d) $650^{\circ} \mathrm{C}$

However, this choice is a rough simplification of the real material behaviour. In particular, it was shown by previous authors $[15,19]$ that the material is viscoplastic at temperatures above $600^{\circ} \mathrm{C}$. For instance, during a relaxation phase, after a loading ramp at $d \varepsilon_{p} / d t=10^{-1} s^{-1}$, the stress decreases by about 8\%, from $1300 \mathrm{MPa}$, down to $1200 \mathrm{MPa}$ within the first two seconds of 
relaxation and then stabilizes around $1000 \mathrm{MPa}$ after 500 seconds of relaxation. This viscous nature of the material is not taken into account in this model, although it will be extended to viscoplastic material behaviours in the future. The global plasticity model for the crack tip region is now formulated only for elastic-plastic material behaviours for three reasons.

First, the viscoplastic nature of the N18 nickel base superalloy only becomes non negligible above $600^{\circ} \mathrm{C}$ and it is considered by our industrial partner (Snecma) that thermal excursions above $600^{\circ} \mathrm{C}$ are brief and should be considered as exceptions.

Second, the interpolation of the material parameters between the different temperatures requires that the same material model is employed from $450^{\circ} \mathrm{C}$ up to $650^{\circ} \mathrm{C}$.

And finally, it was also observed by previous authors that, under vacuum conditions, the fatigue crack growth rate at $650^{\circ} \mathrm{C}$ is the same for triangular fatigue cycles (10 sec loading - $10 \mathrm{sec}$ unloading) and for fatigue cycles including a dwell time (10 sec loading - $300 \mathrm{sec}$ dwell - $10 \mathrm{sec}$ unloading). On the contrary, under ambient air conditions, the addition of a dwell time increases the fatigue crack growth rate by about a factor 2. Therefore, it was considered that more attention should be put, in this case, on the modelling of the effect of the environment rather than on the viscous behaviour of the material.
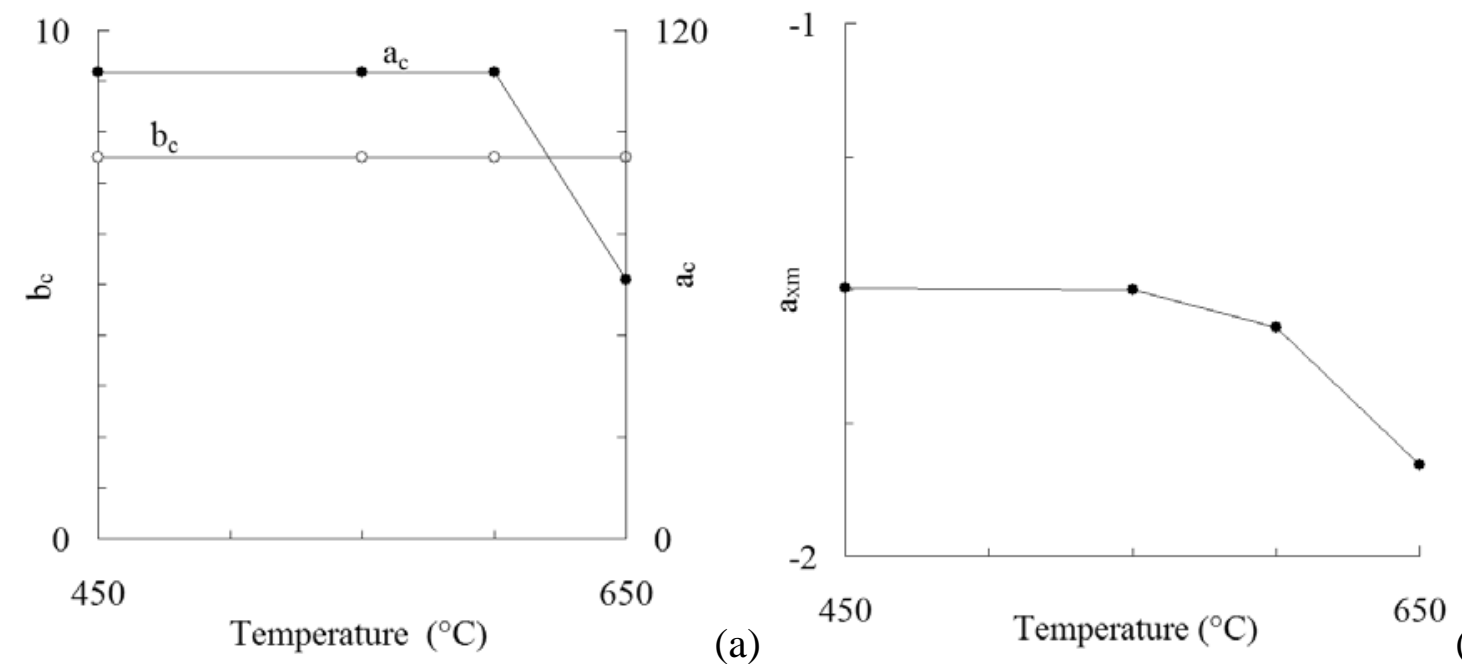

Figure 3. Example of parameters evolutions with temperature. (a) $b_{c}$ and $a_{c}$, (b) $a_{x m}$.

Then, using the multiscale approach discussed above, the various material parameters $\left(\mathrm{P}_{\mathrm{i}}\right)$ of the global cyclic elastic-plastic constitutive model $f$ are identified for each temperature for the N18 nickel base superalloy and interpolated for intermediate temperatures as piecewise linear functions (Fig. 3). For instance, the two parameters $b_{c}$ and $a_{c}$ are used to predict how the elastic domain of 
the cyclic plastic zone moves when plastic deformation occurs (domain E in Fig. 1). In constant amplitude fatigue and in the absence of crack closure, the model predicts that $\Delta \rho_{I}=\left\langle\Delta K_{I}^{\infty}-b_{c}\right\rangle^{2} / a_{c}$. In the present case $b_{c}$ and $a_{c}$ are found to remain constant below $600^{\circ} \mathrm{C}$. Above $600^{\circ} \mathrm{C}, b_{c}$ remains constant, while $a_{c}$ decreases (Fig. 3 a). The parameter $a_{x m}$ is used in the evolution equation of the crack opening level $\left(K_{o p}\right)$ versus plastic deformation $\left(\partial \phi_{x m} / \partial \rho_{I}=a_{x m} \sqrt{\phi_{x m}}\right.$, where $\left.\phi_{x m}=K_{o p}^{2}\left(1-v^{2}\right) / E\right)$. It is observed, from FE computations, that $a_{x m}$ is negative (the crack opening level diminishes when the crack blunts $d \rho_{I}>0$ ) and that it diminishes with temperature.

$$
\frac{d \rho_{I}}{d t}=f\left(\frac{d K_{I}^{\infty}}{d t}, V_{\text {int }}^{j}, P^{i}(T)\right) \quad \text { and } \quad \frac{d V_{\text {int }}^{j}}{d t}=f_{j}\left(\frac{d \rho_{I}}{d t}, \frac{d a}{d t}, P^{i}(T)\right)
$$

In this form the model allows computation of $d \rho_{I} / d t$ and of the rate of variation of the internal variables for complex load histories including temperature variations.

\subsection{Crack propagation law}

A crack propagation law is also introduced that defines the rate of creation of cracked area per unit length of the crack front $(d a / d t)$ as a function of $d \rho_{I} / d t$. It is typically proposed that the crack propagation rate obeys Eq. 3, where $\alpha$ is a parameter to be adjusted using a high frequency and constant amplitude fatigue crack growth experiment (sinus, $\mathrm{R}=0.05, f=0.5 \mathrm{~Hz}$ ).

This approach was applied to mode I fatigue crack growth at a moderate temperature $\left(550^{\circ} \mathrm{C}\right)$ and validated using constant amplitude and complex fatigue crack growth experiments. At $550^{\circ} \mathrm{C}$ the effect of a dwell time on fatigue crack growth is negligible (Fig. 4). As a matter of fact, the fatigue crack growth rate measured using triangle cycles at $0.5 \mathrm{~Hz}$ (1-1) or cycles including a dwell time of 300 seconds (10-300-10) is nearly the same (Fig. 4).

Then the fatigue crack growth rate was determined for complex cycles, and plotted versus the maximum stress intensity factor range of the complex cycle. These complex cycles are constructed as follows : after a 10 seconds loading ramp, the sample is partially unloaded (by $\mathrm{x} \%=0 \%, 10 \%$ or 20\%) and then either 5 or 10 secondary cycles are applied, before the sample is fully unloaded. This type of cycle was also employed by previous authors, for instance, by Chassaigne et al. [15]. It is observed that the fatigue crack growth rate per block measured when complex cycles are used is about twice that obtained using (1-1) or (10-300-10) cycles. 
It is interesting to compare the predictions of this model with what would be predicted using a more classical approach, namely the Paris law and a Rainflow counting method. With this approach, the parameters of the Paris law are determined using the $d a / d N-\Delta K$ curve obtained with triangular cycles ( $\mathrm{f}=0.5 \mathrm{~Hz}, \mathrm{R}=0.1$ ) and then employed to predict the fatigue crack growth rate for complex cycles (Fig. 4). The predicted crack growth rate is greater than the experimental one by about a factor 5. As a matter of fact, with this approach, a secondary cycle is considered as fully efficient, since its stress ratio is high enough to keep the crack open. Therefore the contribution of secondary cycles to fatigue crack growth is overestimated.

On the contrary, using the model proposed herein the fatigue crack growth rate is successfully predicted for complex cycles since a large part of a secondary cycle is considered as inefficient. As a matter of fact, the crack growth rate $d a / d t$ is proportional to the plasticity rate $d \rho_{I} / d t$, therefore when $d \rho_{I} / d t$ is null the crack does not grow. This happens when the crack is closed, but this happens also during a secondary cycle, when the effective stress intensity factor range is below the size of the elastic domain of the crack tip region (E in Fig. 1). Therefore, introducing an elastic domain is analogous to introducing an intrinsic non propagation threshold stress intensity factor range $\Delta K_{t h}^{\text {int }}$. These results confirm that at least two criteria should be fulfilled to get fatigue crack growth, $K_{\operatorname{Im} a x}^{\infty}$ should be over $K_{o p}$ and $\Delta K_{I}^{\infty}$ should be over $\Delta K_{t h}^{\text {int }}$. In this model, the current values of $K_{o p}$ and $\Delta K_{\text {th }}^{\text {int }}$ are calculated continuously during any variable amplitude loading scheme. 


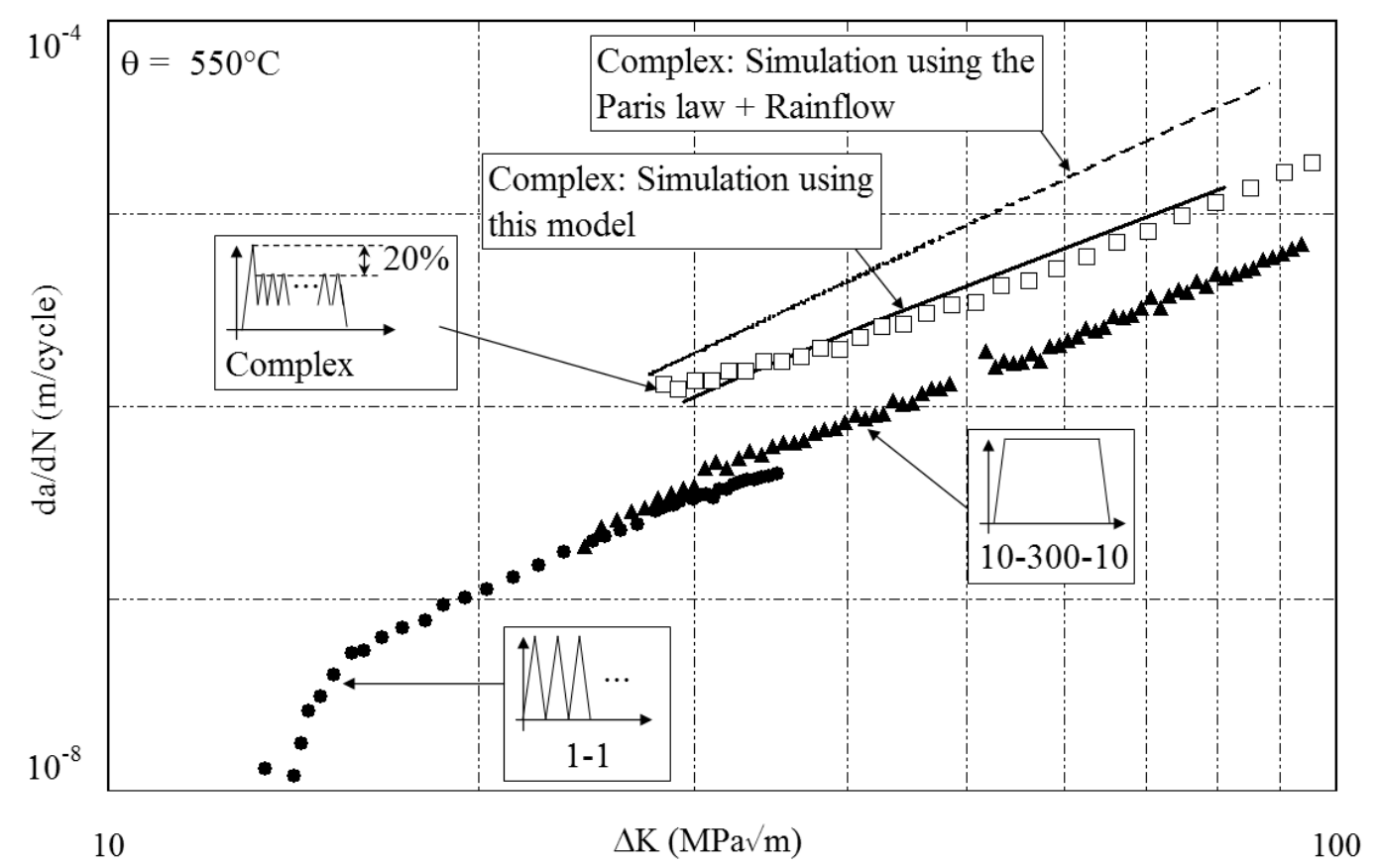

Figure 4. Fatigue crack growth rate in CT specimens at $550^{\circ} \mathrm{C}$ in the $N 18$ nickel base superalloy. Symbols correspond to experiments and lines to predictions.

However, since the fatigue crack growth at high temperature is aimed to be modelled, the phenomenon of oxidation that assists fatigue crack growth should also be considered [20-24]. This mechanism is responsible, for instance, for the detrimental effect of dwell times at temperatures in the N18 nickel base superalloy above $550^{\circ} \mathrm{C}$ [15-19]. As a matter of fact, the grain boundaries are oxidized ahead of the crack tip. As a result, it is observed that the crack path changes from transgranular to intergranular when a dwell time at maximum stress is added to the fatigue cycle. This mechanism is thermally activated. Besides, the material is designed to develop a passivation layer of oxides which protects the material against grain boundary oxidation. This second mechanism is also thermally activated [15,19, 20-23].

Thus, at the beginning of a dwell time, grain boundary oxidation takes place at the crack tip and the crack propagates, but as soon as the passivation layer has grown this propagation stops. Consequently, it was shown, by Chassaigne et al. [15] that only the first seconds of a 300 sec dwell time contribute to crack growth. However, if the crack tip is stretched the passivation layer breaks and the competition between grain boundary embrittlement and the growth of a passivation layer takes place again. Therefore a coupling effect appears between fatigue (mechanical loading) and oxidation. This explains, in particular, why the crack growth rate is not only sensitive to the duration of the fatigue cycle but also to its shape. 
This was demonstrated by Hochstetter et al. [19]. At $575^{\circ} \mathrm{C}$, two types of cycles were used, slow-fast and fast-slow cycles, with the same duration but a different shape. During a fast-slow cycle, the passivation layer is broken during loading, but since the duration of the loading phase is small the detrimental effect of the environment is reduced. Then, at unloading, the passivation layer grows within a few second and protects the material during the rest of the unloading phase. On the contrary, during a slow-fast cycle, the passivation layer breaks and grows continuously during the loading phase. Since the duration of the loading phase is long in that case, oxidation can assist fatigue crack growth. It is therefore observed that the crack growth rate is around twice as high using slow-fast cycles than using fast-slow cycles at $575^{\circ} \mathrm{C}$ (Fig. 5).

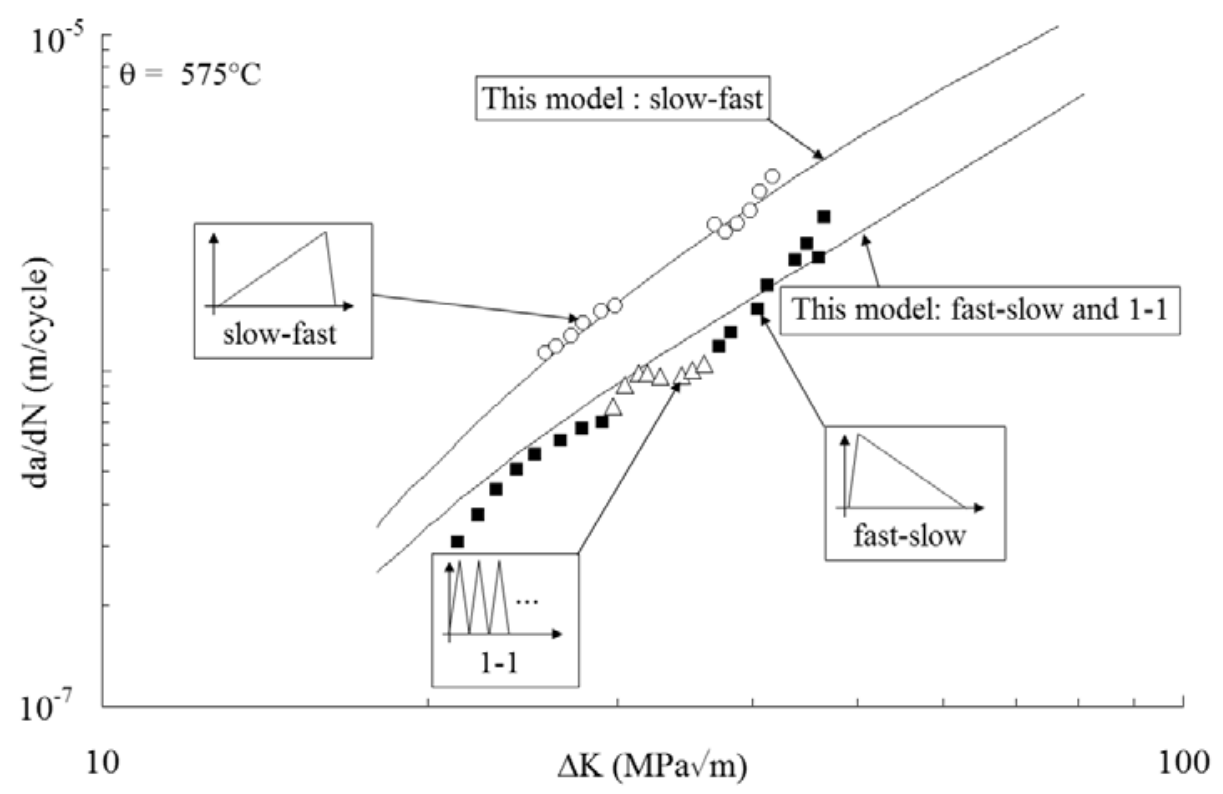

Figure 5. Fatigue crack growth rate in CT specimens at $575^{\circ} \mathrm{C}$ in the $N 18$ nickel base superalloy [19]. Symbols correspond to experiments and lines to predictions.

These phenomena are modelled as follows. The crack growth rate is now the sum of two terms, the first term is due to crack tip plasticity (Eq. 3) while the second term accounts for the contribution of the time during which grain boundary oxidation takes place:

$$
\frac{d a}{d t}=\left(\frac{\partial a}{\partial \rho_{I}}\right) \frac{d \rho_{I}}{d t}+\frac{\partial a}{\partial t}=\underbrace{\alpha(T) \frac{d \rho_{I}}{d t}}_{E q .3}+\frac{\partial a}{\partial t}
$$

The global cyclic elastic-plastic constitutive model, which provides $d \rho_{I} / d t$, is function of the temperature through the dependency of the material cyclic elastic-plastic behaviour to the temperature. Besides, the adjustable parameter $\alpha$ may also be function of the temperature. This 
parameter was determined using fatigue crack growth experiments for which the contribution of the environment is assumed to be negligible (1-1 cycles). For this purpose, it was checked that the crack path is transgranular during these experiments. The identification of $\alpha$ was performed independently at $450^{\circ} \mathrm{C}, 550^{\circ} \mathrm{C}, 600^{\circ} \mathrm{C}$ and $650^{\circ} \mathrm{C}$ and then interpolated as a piecewise linear function (Fig. 6).

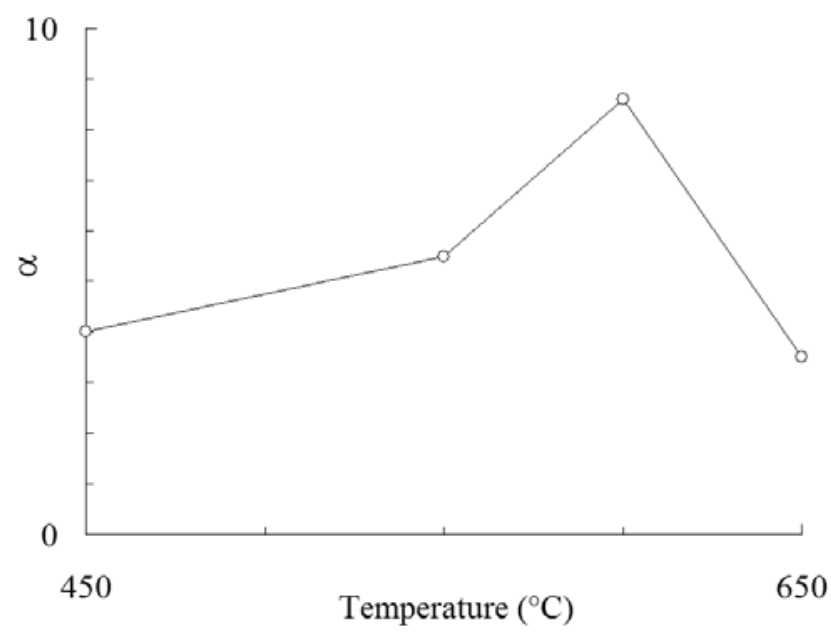

Figure 6. Evolution of the coefficient $\alpha$ (Eq. 3) with temperature. $\alpha$ is adjusted for each temperature so as the simulations coincide with experiments $(R=0.1$ and $f=0.5 \mathrm{~Hz})$ for which the crack path is transgranular.

Then, the second term of this equation (Eq. 4) corresponds to the contribution of grain boundary embrittlement by the chemical environment to the fatigue crack growth rate. The physical mechanisms at the origin of the coupling between fatigue and environment have been discussed by other authors in previous publications $[15,19,24]$. In this paper, we propose very simple partial derivative equations to represent these mechanisms and the experimental campaign that should be performed so identify the parameters in these equations.

Since grain boundary embrittlement stems from a diffusion process, it was assumed to be thermally activated (Eq. 5). Its activation energy $Q$ corresponds to the activation energy of selfdiffusion in nickel at grain boundaries. This part of the fatigue crack growth equation accounts for various effects of time, dwell time effects and frequency effects for instance.

$$
\frac{\partial a}{\partial t}=m \cdot \beta=m \cdot \beta_{o} \exp \left(-\frac{Q}{k T}\right)
$$

The contribution of the environment is assumed to be the product of two terms $m$ and $\beta$. The 
crack growth rate $\beta$ by grain boundary embrittlement, in the absence of any passivation layer, is modulated by the variable $m$ that stands for the state of that passivation layer. When $m=1$, the passivation layer is broken, and the crack growth rate by grain boundary embrittlement is maximum. When $m=0$, the passivation layer is thick enough to fully protect grain boundaries against oxidation.

In between, three adjustable parameters are introduced so as to control the variations of $m$. A first parameter $R_{G}$ is introduced to represent the growth rate of that passivation layer versus time (Eq. 6):

$$
\frac{\partial m}{\partial t}=-R_{G} \cdot m
$$

The easiest method to precisely identify this parameter, would be to compare the fatigue crack growth rate for fatigue cycles with increasing dwell times (10-xx-10). In practice, we only had at our disposal 1-1 cycles, 10-10 cycles and 10-300-10 cycles. However, previous results from J.C. Chassaigne [15] allowed a more precise determination of the value of $R_{G}$. In this study [15], the authors have superimposed a mechanical cycle (10-300-10) with an air pressure cycle. The air pressure is imposed during the dwell time, with a controlled duration.

Then, it is also assumed that the passivation layer is brittle. It breaks in tension and thickens in compression. Therefore, a second parameter $R_{F}$ is introduced so as to model how the rupture of the oxide layer increases the crack growth rate by grain boundary embrittlement. It is assumed that the oxide layer breaks when the crack tip is stretched because of crack tip plasticity (Eq. 7). It happens only at opening, when $d \rho_{I}$ is positive.

$$
d \rho_{I} \geq 0 \Rightarrow \frac{\partial m}{\partial \rho_{I}}=-R_{F} .(1-m), d \rho_{I}<0 \Rightarrow \frac{\partial m}{\partial \rho_{I}}=0
$$

It is worth noting that $\Delta \rho_{I}$ is found to increase with $\Delta K_{I}$ during the simulation of a constant amplitude fatigue crack growth experiment (using the global cyclic elastic plastic model for the crack tip region). Therefore, the value chosen for $\mathrm{R}_{\mathrm{F}}$ in Eq. 7 modifies the slope of the simulated $d a / d N-\Delta K$ curve in the Paris diagram, which was useful in identifying this parameter.

Finally, a third parameter $R_{U L}$ is also introduced to account for the variation of the thickness of the oxide layer when it is elastically deformed (Eq. 8). Only the unloading phase is considered in 
this case:

$$
d K_{I} \leq 0 \Rightarrow \frac{\partial m}{\partial K_{I}}=R_{U L} \cdot m^{2}, d \rho_{I}>0 \Rightarrow \frac{\partial m}{\partial K_{I}}=0
$$

This last equation represents the beneficial effect of a partial underload before the application of a dwell time on the fatigue crack growth. In order to identify the parameter $R_{U L}$ using fatigue crack growth experiments, we had at our disposal the results of an experimental campaign at $550^{\circ} \mathrm{C}$ for $10-300-10$ cycles with either a $10 \%$, a $20 \%$ or a $30 \%$ underload before the dwell time is applied.

Finally, using the set of experimental results, it was possible to determine the various parameters for temperatures ranging between $450^{\circ} \mathrm{C}$ and $650^{\circ} \mathrm{C}$. $\mathrm{R}_{\mathrm{G}}$ and $\mathrm{R}_{\mathrm{F}}$ were determined at each temperature and then were interpolated for intermediate temperatures by a thermally activated function. The activation energy $Q$ was found empirically using the values determined at $450^{\circ} \mathrm{C}$, $550^{\circ} \mathrm{C}, 600^{\circ} \mathrm{C}$ and $650^{\circ} \mathrm{C}$ and its value is close to that given in the literature for the activation energy of self-diffusion in nickel at grain boundary [25]. $R_{U L}$ was only determined at $550^{\circ} \mathrm{C}$ and was assumed to be independent of the temperature.

This model was validated using complex isothermal fatigue crack growth experiments. For instance, it was possible to reproduce the difference between fast-slow and slow-fast fatigue crack growth experiments (Fig. 5) [19]. This result is interesting because the parameters were only identified at $450^{\circ} \mathrm{C}, 550^{\circ} \mathrm{C}, 600^{\circ} \mathrm{C}$ and $650^{\circ} \mathrm{C} .575^{\circ} \mathrm{C}$ is an intermediate temperature and allows validation of the interpolation of the parameters. It also successfully reproduces the effect of the shape of the fatigue cycle that was observed in the experiments, though this type of cycle was never used during the identification phase.

In Fig. 7, the comparisons between some fatigue crack growth experiments performed at $550^{\circ} \mathrm{C}$ and $650^{\circ} \mathrm{C}$ and the corresponding simulations are reported. The agreement is satisfactory for the whole experimental database on CT samples. 

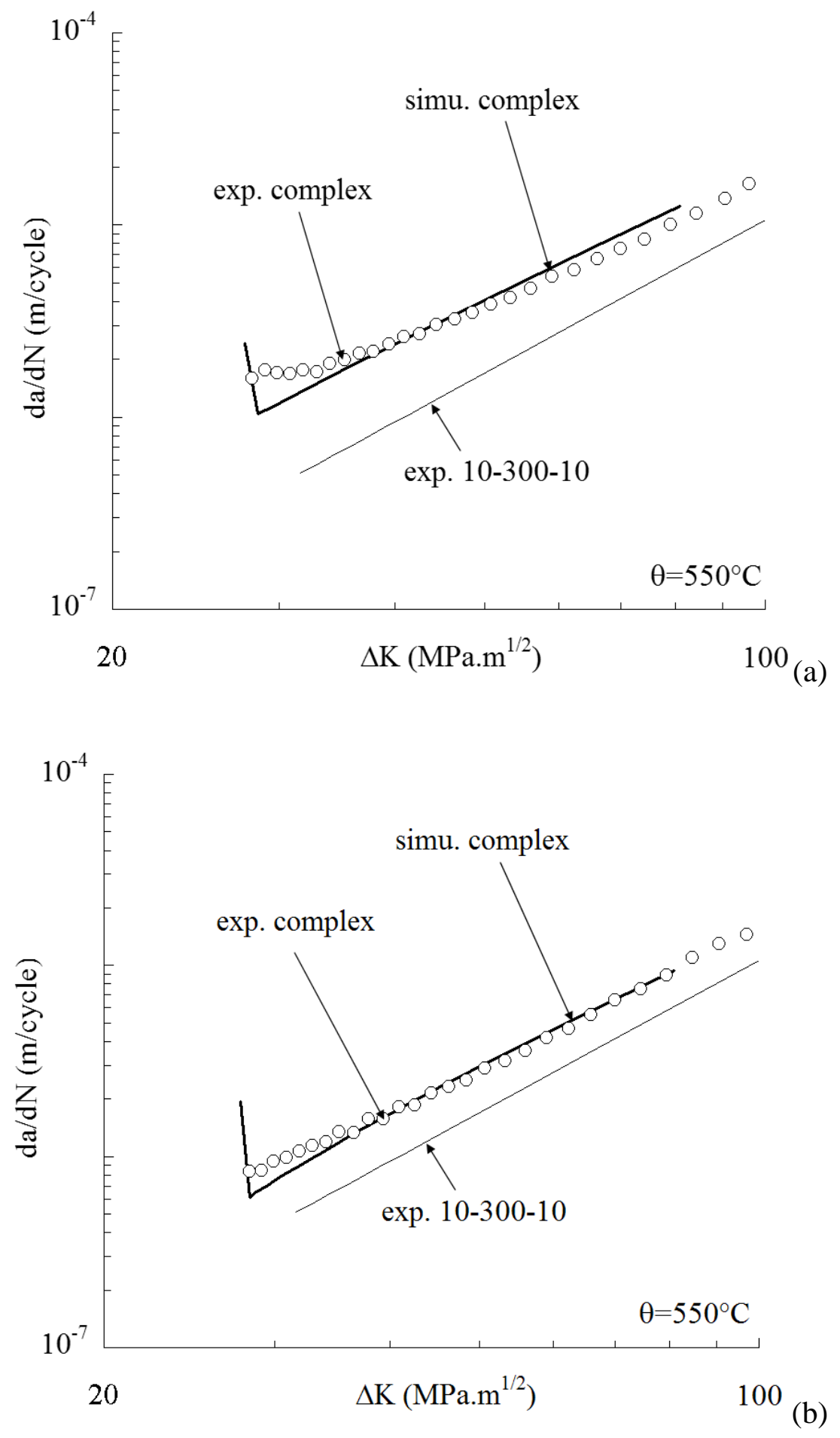


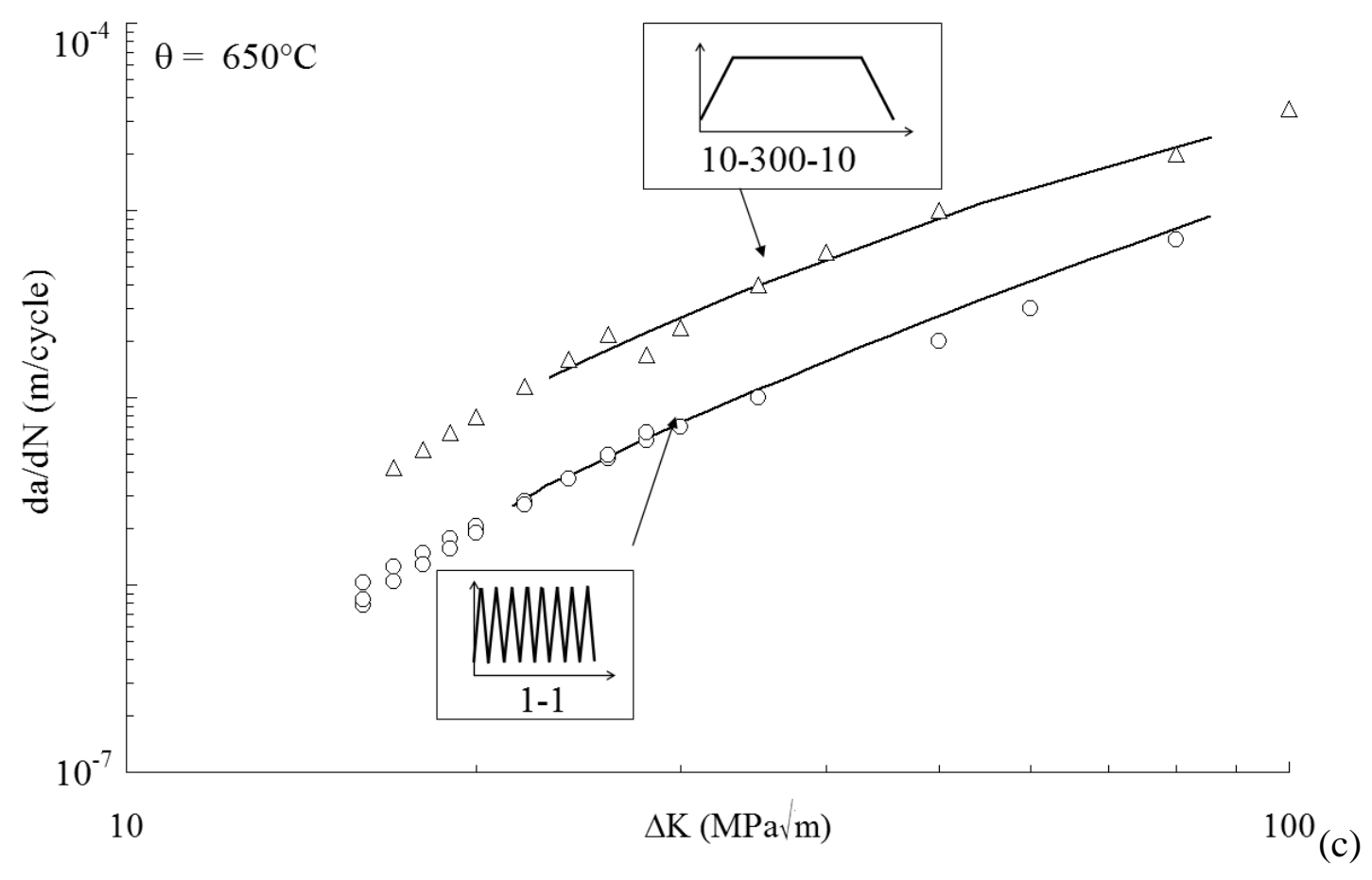

Figure 7. Fatigue crack growth rate in CT specimens in the N18 nickel base superalloy. Symbols correspond to experiments and lines to the simulations using this model. (a) complex cycles with 10 sec loading, 5 secondary cycles and $10 \mathrm{sec}$ unloading at $550^{\circ} \mathrm{C}$. (b) complex cycles with $10 \mathrm{sec}$ loading, $10 \%$ of unloading, 5 secondary cycles and $10 \mathrm{sec}$ unloading at $550^{\circ} \mathrm{C}$. (c) $1-1$ cycles and 10-300-10 cycles at $650^{\circ} \mathrm{C}$.

\subsection{Validation}

Finally, once the model is identified between $450^{\circ} \mathrm{C}$ and $650^{\circ} \mathrm{C}$ and validated for isothermal 1-1 cycles, 10-300-10 cycles and complex cycles in a database of experimental $d a / d N-\Delta K$ curves obtained using CT specimens, it is also validated using more complex fatigue crack growth experiments. Symmetric and non-symmetric double notched samples are used with quarter-elliptic and semi-elliptic cracks, at $450^{\circ} \mathrm{C}, 550^{\circ} \mathrm{C}$ and $650^{\circ} \mathrm{C}$.

For example, the information regarding the results plotted in Fig. 8 are gathered in Table 2. In Fig. 8, the number of cycles to failure obtained in the experiments is plotted against the predicted fatigue life.

The predictions of the model discussed in this paper (black symbols) are compared with those obtained with a more conventional approach (empty symbols). That approach consists of a rainflow counting method to extract fatigue cycles from a "mission", then it uses the Paris law and the Walker closure model to predict the fatigue crack growth rate for various stress ratios 
$\left.(d a) d N=C_{\text {fatigue }} \Delta K_{e f f}{ }^{m_{-} \text {fatigue }}\right)$ and finally the effect of dwell times is taken into account through a “pseudo-creep” law $\left(d a / d t=C_{\text {creep }} K(t)^{m_{-} \text {creep }}\right)$. Since that previous model was identified carefully using 1-1 cycles and 10-300-10 cycles at each temperature, for these cycles a good agreement with the experiments is obtained either with the previous model or with the model proposed in this paper.

On the contrary, when more complex cycles are used (Fig. 8), there is a clear improvement of the predicted number of cycles by using the model proposed herein by comparison with the previous model. This improvement is found either for quarter-elliptic or semi-elliptic cracks.

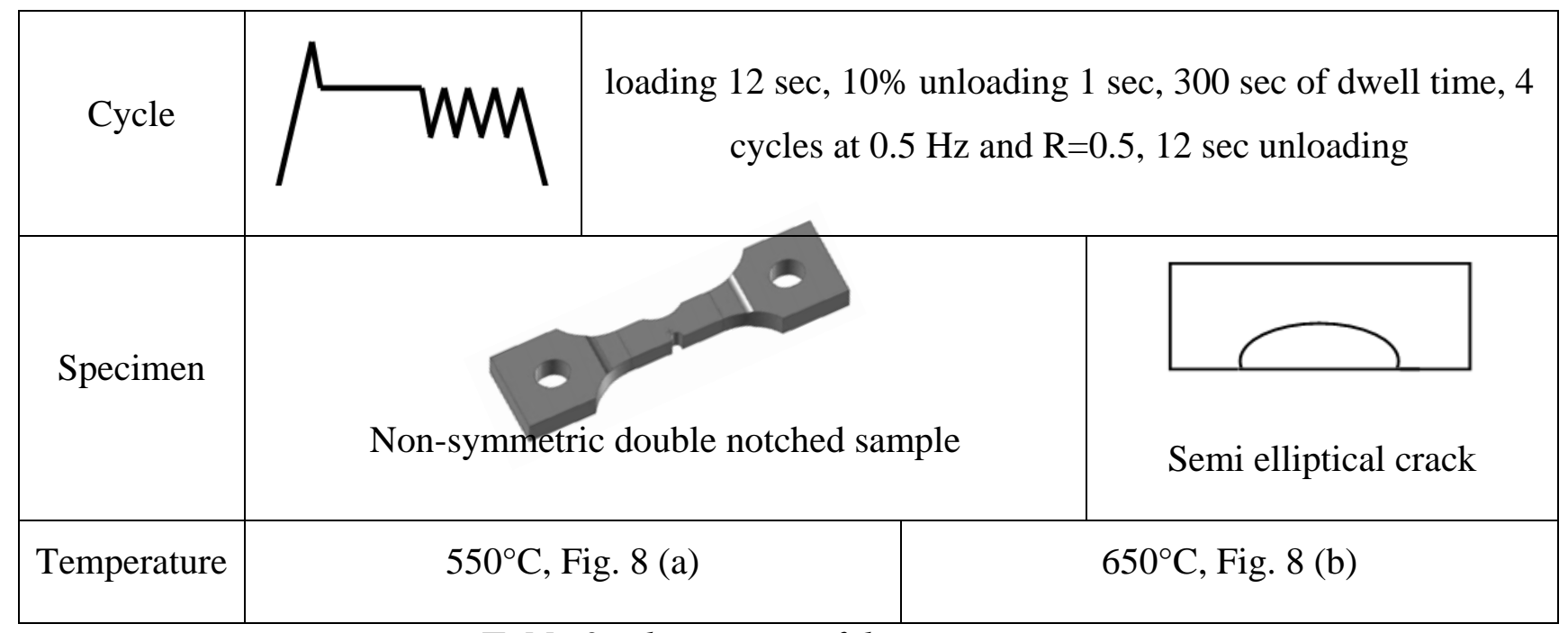

Table 2 : description of the experiments.

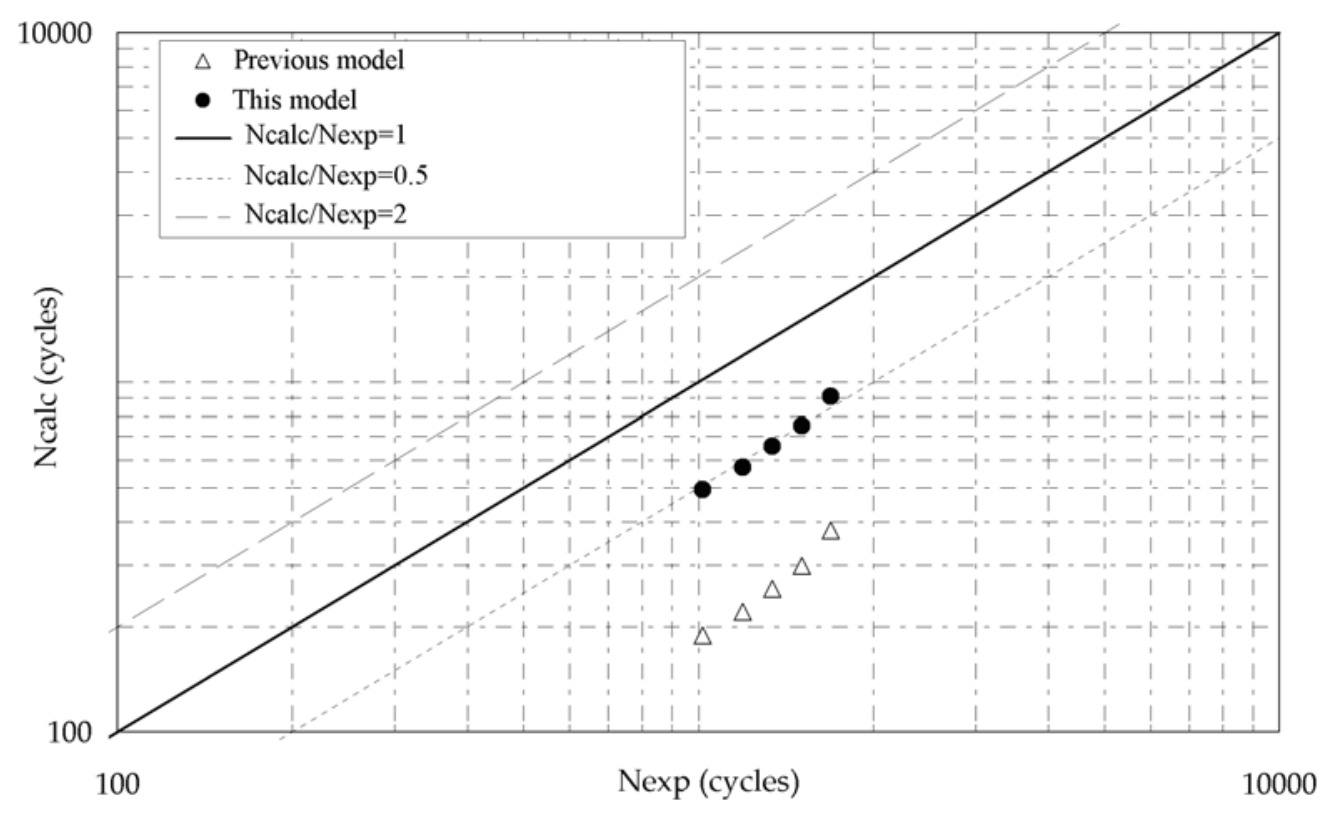




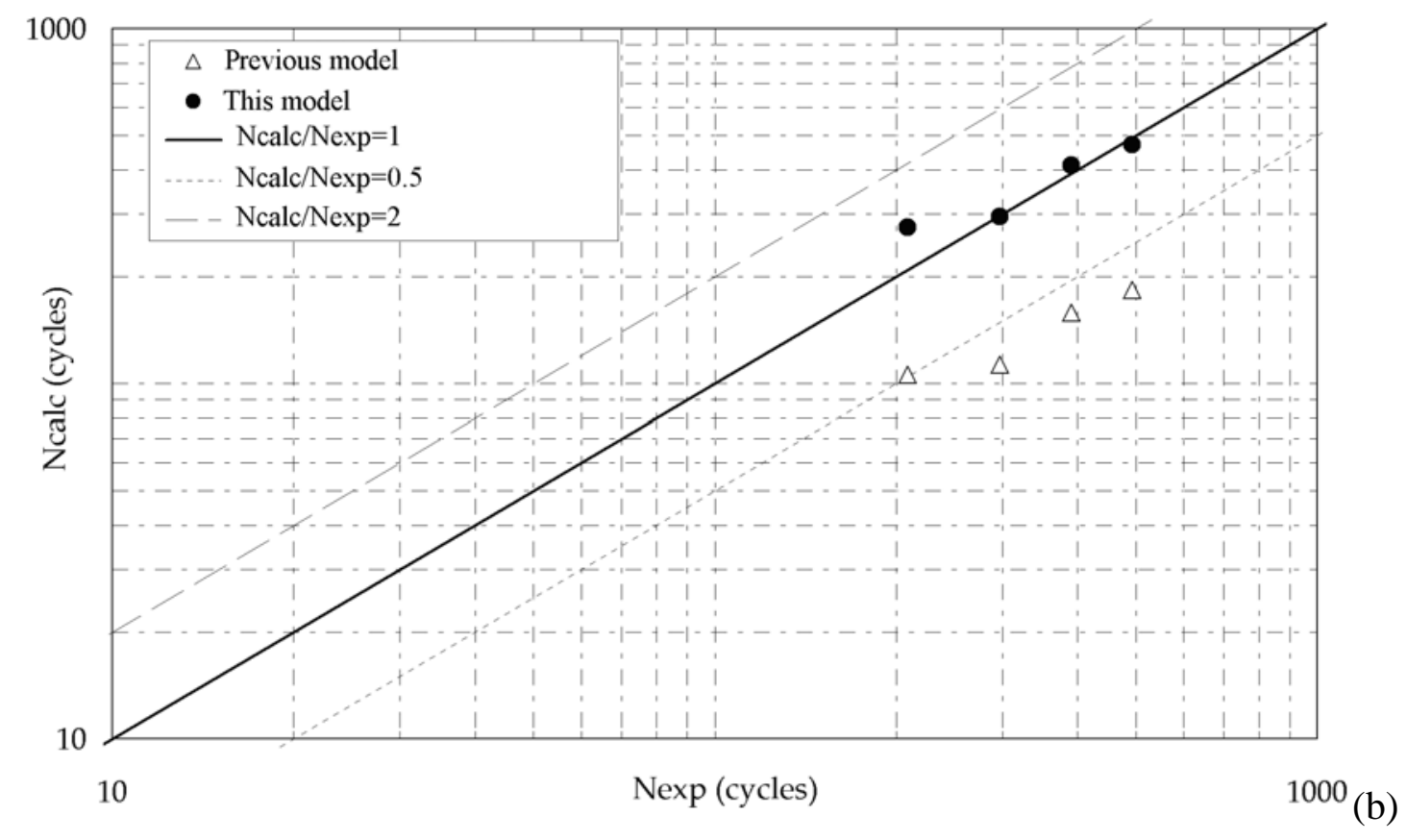

Figure 8. Number of cycles predicted either using the model proposed herein (black symbols) or using a more conventional approach which include a rainflow counting method, the Paris law and the Walker equation for fatigue and a creep law to account for dwell times (empty symbols). (a) $550^{\circ} \mathrm{C}$, (b) $650^{\circ} \mathrm{C}$.

Finally, the model was also used to simulate non-isothermal fatigue crack growth experiments performed on tubular specimens in the same material (Fig. 9a). Various problems arose. First of all, if the model is used directly to simulate the experiments the agreement between the simulations and the experiments is not satisfactory. A plane strain condition along the crack front was assumed from the beginning, which is not valid for these tubular specimens. To solve this problem, the whole set of parameters for the cyclic elastic-plastic model of the crack tip region was re-identified using the same constitutive behaviour for the material but using a plane stress hypothesis instead of plane strain during the finite element computations. Apart from these parameters, that can be re-identified easily using FE computations, all the other parameters in the model were not modified.

With this new set of parameters it was possible to simulate the fatigue crack growth rate for a non-isothermal cycle, which includes a loading ramp of 10 seconds, a partial unloading of $0 \%, 10 \%$ or $20 \%$ of the maximum load, a dwell time of 300 seconds and finally an unloading ramp of 10 seconds. During this mechanical cycle the temperature is always kept at $450^{\circ} \mathrm{C}$ except during a thermal peak of 20 seconds, that includes a thermal ramp of 10 seconds between $450^{\circ} \mathrm{C}$ and $650^{\circ} \mathrm{C}$ followed by a cooling ramp of 10 seconds between $650^{\circ} \mathrm{C}$ and $450^{\circ} \mathrm{C}$. The peak stress is reached before the peak temperature is reached. The temperature is equal to $550^{\circ} \mathrm{C}$, when the peak stress is 
reached. The temperature is measured using thermocouples positioned on the inner face and outer face of the tubular sample near the hole used to initiate a crack.

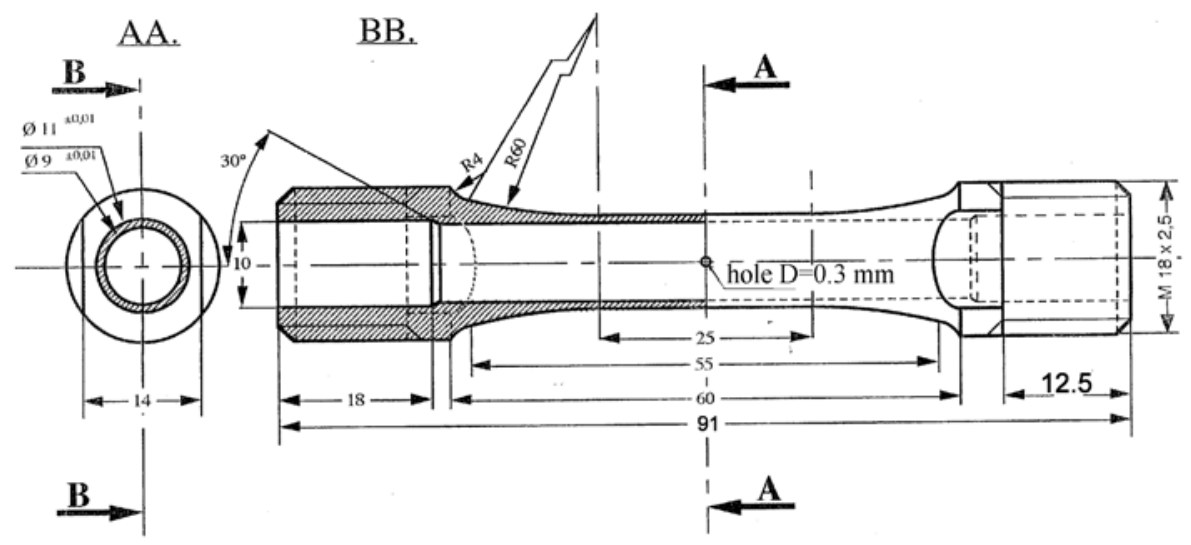

(a)

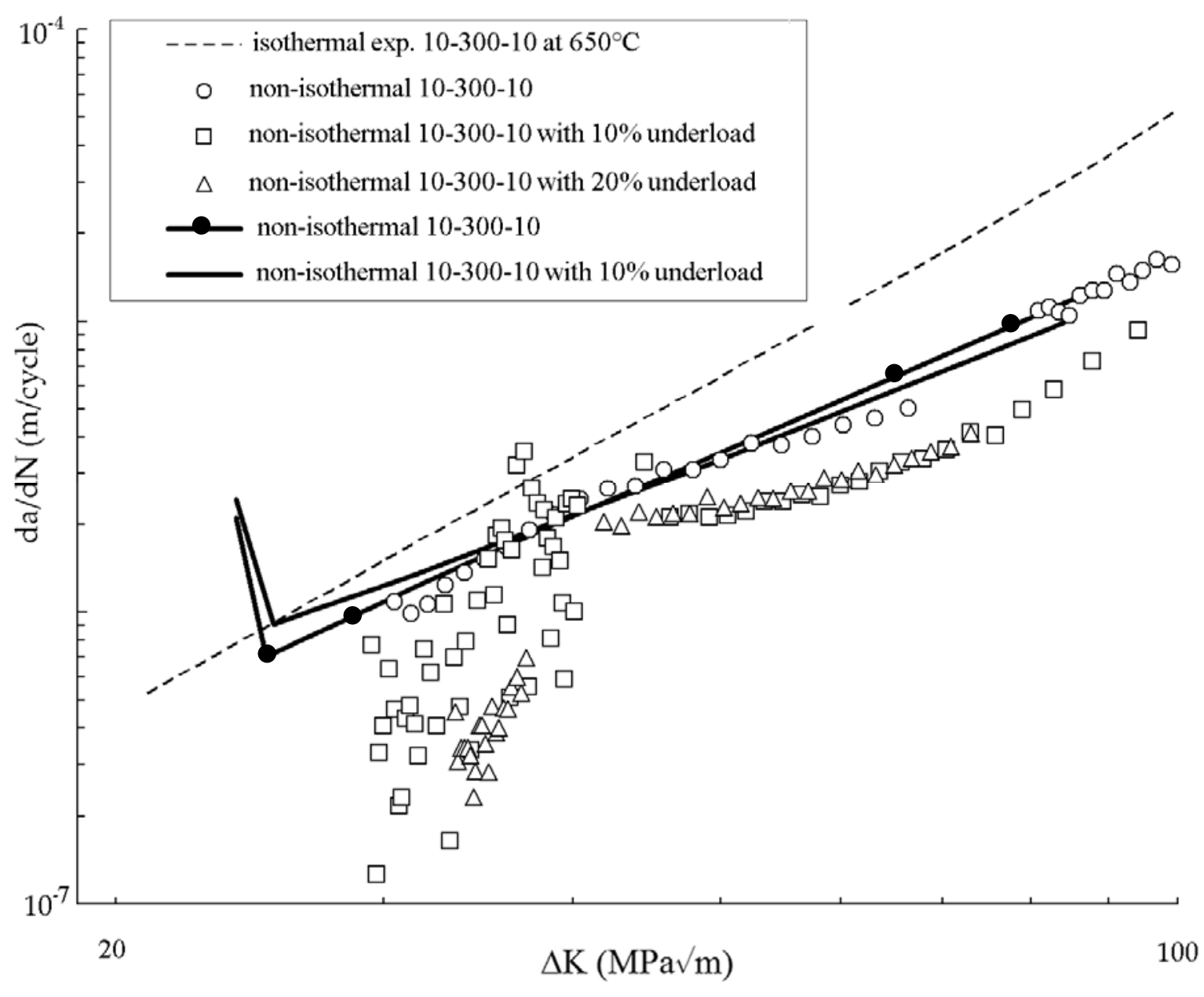

Figure 9. (a) geometry of the tubular sample employed for the experiments. (b) fatigue crack growth rates measured during non-isothermal fatigue crack growth experiments, for complex cycles (empty symbols). These results are compared with the simulations (thick lines). The dotted line is the reference isothermal test at $650^{\circ} \mathrm{C}$ and using a 10-300-10 loading cycle. 
The agreement between the simulations and the experiments is not satisfactory in this case. There is a good prediction of the fatigue crack growth rate for a non-isothermal 10-300-10 cycle, but the effect of a partial underloading at the beginning of the dwell time is not properly represented by the model. The simulations, in this case, predict no difference in the fatigue crack growth rates with the amount of underloading at the beginning of the dwell time, while a difference is observed in the experiments. At the moment, it is not clear whether the model or the experiments should be re-examined. In the future, it would be useful to setup an experiment which would be more representative of the loading conditions in a turbine disk. In particular, a semi-elliptical crack at the surface of a thick sample would be more representative and in this case the plane strain condition along the crack front would apply. However, it is clear that controlling the temperature for such a geometry is more complex than for tubular specimens. Besides, concerning the model, it is questionable that the effect of a partial underload before the application of a dwell time is to be attributed only to the thickening of the passivation layer of oxides during unloading. This approach was successful for isothermal conditions, but other authors have attributed this effect to a local closure effect [15] or to an effect of the viscous behaviour of the material at the crack tip.

\section{Conclusions}

An incremental model has been developed in order to predict fatigue crack growth under variable amplitude loading conditions. The aim of the present research was to examine how to extend the model to non-isothermal loading conditions and how to account for environmentally assisted cracking.

The rate of creation of cracked area per unit length of the crack front $d a / d t$ is assumed to be the sum of a term proportional to the rate of plastic deformation in the crack tip region and of a term accounting for environmentally assisted cracking.

The first part of the model is developed partly using the FE method. A strategy is proposed to transfer to the global scale the very detailed data generated using local FE computations in the crack tip region. Then a simplified model is identified at the global scale that accounts for plasticity induced history effects. This part of the model requires the identification of the constitutive behaviour of the material (push-pull tests) and constant amplitude fatigue crack growth experiments at a frequency high enough to avoid environmentally assisted cracking for various temperatures within the operating temperature range. Then the parameters of the model were interpolated between the identification temperatures, for use in non-isothermal and variable amplitude loading conditions. It was shown that using this approach, the effect of secondary cycles superimposed with 
a dwell time on fatigue crack growth is successfully represented, in particular for high crack growth rates.

The second part of the model aims at modelling the competition between crack growth by grain boundary embrittlement ahead of the crack tip and the growth and fracture of a passivation layer of oxides which is believed to reduce oxygen diffusion along grain boundaries and to protect the material. This part was set up to improve the predictions of the model for low crack growth rates. This competition was modelled by a thermally activated crack growth rate in absence of a passivation layer, modulated by a variable, varying between 0 and 1 , that stands for the state of the passivation layer. It increases to one when the crack tip is stretched, because the passivation layer is assumed to break in tension and decreases to zero progressively when time elapses, so as to account for the growth of the passivation layer. This model allows modelling frequency effects, dwell time effects and also the difference between fast-slow and slow-fast cycles in fatigue crack growth experiments. A third equation was also added to account for the beneficial effect of a partial unloading before the application of a dwell time, which was attributed to the thickening of the passivation layer of oxides during an unloading phase. A good agreement was found under isothermal conditions for fatigue cycles with a dwell time after a partial unloading, but this was not the case for non-isothermal conditions. In the future, the experimental campaign should be enriched so as to identify more precisely this coefficient.

The model was applied to constant amplitude and complex isothermal fatigue tests, for through thickness, semi-elliptical and quarter-elliptical cracks leading to satisfactory results. It was also applied to complex non-isothermal missions on industrial test components for which the results are less satisfactory.

\section{Acknowledgements}

This research was sponsored by SNECMA Moteurs / Safran. The authors would like to thank N. Cosme, B. Burgardt and M. Grange for fruitful discussions.

\section{References}

[1] Forman, R.G., Kearney V.E., Engle R.M. (1967). Numerical analysis of crack propagation in cyclic loaded structures. Journal of basic Engineering, 89, 459-64.

[2] Elber, W. (1971). The significance of fatigue crack closure. ASTM STP 468, 230-242.

[3] Wheeler, O. (1972). Spectrum loading and crack growth. Journal of Basic Engineering, 94, 181186 
[4] Schijve, J. (1999). The significance of fractography for investigations of fatigue crack growth under variable amplitude fatigue. Fat. Fract. of Engng. Mater. Struct., 22, 87-99.

[5] Budianski, B., Hutchinson, J.W. (1978). Analysis of crack closure in fatigue crack growth. J. of Applied Mechanics, Trans. of the ASME, 45 (2), 267-276.

[6] Newman J.C., (1984), A crack opening stress equation for fatigue crack growth, Int. J. Fracture 1984, 24, R131-R135.

[7] Skorupa M (1999) Load interaction effects during fatigue crack growth under variable amplitude loading - a literature review. Part II: qualitative interpretation, Fat. Fract. of Engng. Mater. Struct., 22 (10), 905-926.

[8] Pommier S, Bompard P (2000) Bauschinger effect of alloys and plasticity-induced crack closure: a finite element analysis. Fat. Fract. of Engng. Mater. Struct., 23 (2), 129-139.

[9] Pommier, S. (2003) Cyclic plasticity and variable amplitude fatigue. Int. J. Fatigue, 25 (9-11), 983-997.

[10] Pommier, S., Risbet M, (2005), Time-derivative equations for fatigue crack growth in metals, Int. J. Fract., Vol. 131, pp. 79-106.

[11] Pommier, S., Hamam R., (2007), Incremental model for fatigue crack growth based on a displacement partitioning hypothesis of mode I elastic-plastic displacement fields, F Fatigue Fract Eng Mater Struct, Vol. 30, pp. 582-598.

[12] Hamam R., Pommier, S., Bumbieler, (2007), Variable amplitude fatigue crack growth, experimental results and modelling, Int. J. Fat., Vol. 29, Issue: 9-11, pp. 1634-1646.

[13] Hills, D. A., Kelly, P. A., Dai, D. N. and Korsunsky, A. M. (1996) Solution of Crack Problems, The Distributed Dislocation Technique, Kluwer Academic Publ., Dordrecht.

[14] Grange M., Identification d'une loi de comportement EP pour l'alliage N18 avec représentation de l'évolution de la contrainte moyenne, technical report, Snecma, $\mathrm{YQMM} / 2005 / 0$.

[15] Chassaigne J-C., Fissuration à hautes temperatures du superalliage base nickel N18 élaboré par métallurgie des poudres, étude du couplage mécanique-environnement en pointe de fissure, Thesis of ENSMP, Paris, 1997.

[16] Wlodek S. T., Kelly M., Alden D., « The structure of N18 superalloys », Ed S. D;. Antolovitch et al., T.M.S, 467-476, 1992.

[17] Lautridou J-C., Guedou J-Y., Honnorat Y., Effects of inclusions on LCF Life of PM superalloys for turboengines disks, Conf. high temperature materials for power engineering, eds. Kluwer academics publishers, 1163, 1990.

[18] Lemaitre J., Chaboche J-L., Mécanique des matériaux solides, Dunod, Paris, 2001.

[19] Hochstetter G., Propagation des fissures à haute temperature dans le superalliage N18 pour disques de turbomachine. Interactions entre la nature des sollicitations mécaniques et des effets d'oxydation, Thesis of ENSMP, Paris, 1994. 
[20] Bouvard J-L., Modélisation de la propagation de fissures dans les aubes de turbine monocristallines, Thesis of ENSMP, Paris, 2006.

[21] Kruch S., Chaboche J-L., Prigent S., A fracture mechanics based fatigue-creep-environment crack growth model at high temperatures, Int. J. Press. Vess. And Pipping, 59:141-148, 1995.

[22] J. Tong , S. Dalby , J. Byrne , M.B. Henderson , M.C. Hardy, « Creep, fatigue and oxidation in crack growth in advanced nickel base superalloys », International Journal of Fatigue 23, 897902, 2001.

[23] Woodford G.A., « Gas phase embrittlement and time dependent cracking of nickel based superalloys “Energy Materials, Vol 1, No 1, pp 59-79, 2006.

[24] Vasudevan, A. K., Sadananda, K., Holtz, R.L., Analysis of vacuum fatigue crack growth results and its implications, International Journal of Fatigue 27 (2005) 1519-1529.

[25] Perusin S., Conséquences de l'oxydation haute température sur l'injection de défauts et le comportement mécanique des matériaux métalliques, Thesis de l'Institut Polytechnique de Toulouse, 2004. 